\title{
DESIGN DE MODA AMPLAMENTE SUSTENTÁVEL: ANÁLISE DO CICLO DE VIDA DE ACESSÓRIOS EM COURO
}

Débora Maria de Macedo Quaresma

Universidade Luterana do Brasil - ULBRA

dequaresma@gmail.com

Heloisa Tavares de Moura

Centro Universitário Ritter dos Reis - UniRitter

heloisa@id.iit.edu

Resumo: O presente artigo apresenta o estudo de caso de uma empresa de design de moda, cujos produtos são acessórios feitos de sobras de couro do setor calçadista. Através de análises do ciclo de vida produto-serviço, objetiva a sistematização de abordagens projetuais do design para a sustentabilidade ampliada, integrando as esferas ambiental, social e econômica. A metodologia utilizada neste trabalho teve natureza predominantemente qualitativa, combinando observação contextual, entrevista semiestruturada, e workshop de cocriação. Como desdobramento, propõe um conjunto de critérios, cenários e alternativas, a fim de nortear a atuação da empresa pesquisada em direção a uma prática profissional mais amplamente sustentável.

Palavras-chave: Design de Moda, Sustentabilidade, Ciclo de Vida, Acessórios em Couro.

\begin{abstract}
This article presents the case study of a fashion design company, whose products are accessories made of remains from the footwear sector. Through analyses of the service-product life cycle, it aims to systematize design project approaches for unrestricted sustainability, integrating the environmental, social and economic dimensions. The adopted methodology was predominantly qualitative, combining contextual observation, semistructured interview and co-creation workshop. As a result, it proposes criteria, scenarios and alternative concepts to guide the researched firm to further progress in the sustainability continuum.
\end{abstract}

Keywords: Fashion Design, Sustainability, Life Cycle, Leather Accessories. 


\section{INTRODUÇÃO}

A partir do final da década de 1990, em decorrência da difusão do conceito de sustentabilidade (WCED, 1987), a prática do design sustentável (HIRSCHHORN et al., 1993; WALKER, 2003; MCDONOUGH e BRAUNGART, 2004) começou a ser difundida no mundo, expandindo o enfoque predominantemente ambiental, de modo a incluir as demais dimensões do conceito. Buscava, assim, desenvolver soluções economicamente viáveis, ecologicamente corretas e socialmente equitativas. Do mesmo modo que o ecodesign, favorecia o ciclo de vida do produto desenvolvido, mas também enfatizava a inclusão adicional das necessárias considerações sociais e éticas para a sustentabilidade ampla e de longo termo, sem desconsiderar a viabilidade econômica.

Em parcial convergência, cada vez mais consciente dos resultados do consumo desenfreado, a sociedade tem se tornado crescentemente exigente quanto a soluções e inovações em produtos e práticas que respeitem o meio ambiente. Para chegar a um consumo de fato sustentável, no entanto, é necessária uma mudança extrema nas práticas de produção e consumo vigentes. Conforme Manzini (2005, p. 98), "a sustentabilidade exige inovações sistêmicas radicais baseadas numa redução drástica do consumo e numa nova ideia de bem estar, cujos valores regenerem o tecido social, econômico e ambiental".

O desafio, por conseguinte, é crescer, em termos de desenvolvimento, ao mesmo tempo que incrementando questões relacionadas às dimensões ambiental e social da sustentabilidade, gerando uma nova consciência a respeito do consumo de bens e produtos. Em um contexto global de preocupação com os recursos naturais do planeta, e influenciadas pelos esforços liderados pela Organização das Nações Unidas (ONU), foram criadas várias instituições, organizados eventos internacionais e produzidos documentos passíveis de preservar os valores reputados como prevalentes conjunto de toda a humanidade (MOURA, 2013). No Brasil, destaca-se a Lei de Resíduos Sólidos (BRASIL, 2010), visando o gerenciamento desses resquícios por meio de etapas articuladas entre si, desde a não geração de novo resíduo até a disposição final dos mesmos, com ações compatíveis entre governo, iniciativa privada e consumidores mais conscientes quanto ao excessivo consumo.

Nesse cenário, pode-se afirmar que tais iniciativas, dentre outras, influenciam direta e indiretamente as empresas e governos na geração e produção de matériasprimas e resíduos. Como resultado, rotineiramente, percebe-se, nas indústrias, uma maior preocupação quanto às formas de minimizar os impactos ambientais, em qualquer segmento, além de outras questões relativas aos demais pilares da sustentabilidade.

O presente artigo discute o design de moda amplamente sustentável dentro da indústria de acessórios de moda e, nele, o papel e contribuição do design, através de abordagens projetuais sistemáticas, considerando o ciclo de vida do sistema produtoserviço (MANZINI \& VEZZOLI, 2002, 2004; VEZZOLI \& MANZINI, 2008; VEZZOLI \& CESCHIN, 2008). Para esse fim, a partir da revisão bibliográfica, a metodologia qualitativa (CRESWELL, 2007, p. 186) é a que melhor se aplica aos objetivos deste trabalho, uma vez que permite ao pesquisador a inserção no "cenário natural" em que está situado o seu objeto de estudo, desenvolvendo-se, através do estudo de caso de empresa de acessórios de moda em couro, combinando observações contextuais, 
entrevistas semiestruturadas com empresários, funcionários e clientes, e workshop de cocriação, a fim de mapear um ciclo atual da empresa e possíveis estratégias futuras.

\section{CICLO DE VIDA DO SISTEMA PRODUTO-SERVIÇO}

Esta discussão considera o ciclo de vida como um processo que não se restringe somente aos bens, estendendo-se também aos serviços, numa concepção de "serviços verdes" (MANZINI \& VEZZOLI, 2002). Para os autores, o caminho para a constituição de uma cultura de consumo sustentável parte do pressuposto da orientação aos consumidores para produtos, bem como para consumo sustentável. Para tanto, é necessário que se executem intervenções sistêmicas (sistema-consumo) e sistemáticas (planejamento). As intervenções sistêmicas dizem respeito ao reconhecimento do sistema consumista não sustentável que é encontrado atualmente, para confrontá-lo com um consumo mais equilibrado e criterioso. Para esse fim, é preciso interferir nas orientações de consumo vigentes. Contudo, são necessárias intervenções sistemáticas, ou seja, deve-se formular e executar um planejamento estratégico que preveja de que modo as demais intervenções ocorrerão, com seus respectivos objetivos e metas.

Para Vezzoli e Manzini (2008), o papel do design pode ser resumido de uma maneira geral, como a atividade responsável por tornar algo tecnologicamente viável e ecologicamente correto, e que deve refletir a origem de novas propostas socioculturais significativas. Um produto-serviço sustentável, em todas as esferas, deverá ser entendido e analisado como aquele que atende às necessidades humanas, respeitando aquelas de outras espécies e ecossistemas, de forma a prolongar a vida na Terra. 0 papel do designer, assim, é identificar de que forma pode desenvolver produtos que sejam amplamente sustentáveis de fato. Para cada área, é possível identificar a forma com o qual tal objetivo pode ser promovido: através do uso de materiais, ou do prolongamento da duração dos produtos, ou da criação de um laço afetivo entre os consumidores e os produtos.

Em Best (2006), são sugeridas três ferramentas para auxiliar as equipes de projeto a compreenderem as considerações sobre os produtos e serviços das empresas dentro de uma organização. Dentre elas, o ciclo de vida do produto (CVP), o qual pode ser um diagrama das fases de vida do mesmo, desde aquisição da matériaprima até o seu destino final (o consumidor). Essa ferramenta pode demonstrar o modo com o qual as vendas ocorrem, de acordo com os novos segmentos de mercado, e como irá se comportar ao longo de seu ciclo, até a sua queda como produto consumido. Esse modelo é útil para antecipar as reações do mercado e desenvolver mecanismos de inovação, com foco no redesign dos produtos. Auxilia também a determinar quando deverá ser desenvolvida e lançada uma nova versão dos produtos, visando à substituição de um produto já existente.

Nesta pesquisa, emprega-se, como ferramenta, o ciclo de vida do produto para identificar os aspectos de produção da empresa analisada. Em Bellgran e Säfsten (2010), os autores afirmam que o sistema de produção deve compreender o todo envolvido: materiais, pessoas, máquinas/equipamentos e instalações. Para os autores, há redução de risco das pessoas no sistema quando a organização do trabalho e o ambiente de trabalho, que são partes importantes do sistema, são desenvolvidos em paralelo com o sistema técnico de produção. Observando o sistema de produção com uma visão holística, torna-se mais fácil de visualizar as várias fases do ciclo de vida, da 
mesma forma que as mesmas podem afetar uns aos outros, e como os recursos devem ser empregados para eliminar ou reduzir os problemas.

Dessa maneira, é possível, também, aplicar esse conceito, bem como incluir questões de sustentabilidade ao longo do ciclo de vida do produto. Para isso, foram pesquisados alguns autores que consideram a sustentabilidade no processo de design de produtos e de serviços. Existem outras ferramentas que podem ser empregadas em uma análise inicial da "organização para a identificação das potencialidades e pontos fracos dentro do processo de produção e design" (BEST, 2006, p.30).

Essa ferramenta é igualmente utilizada para a compreensão do posicionamento da empresa no mercado, assim como o estabelecimento das forças e fraquezas, ou análise SWOT, do modelo de negócio praticado pela mesma. A mesma pode, então, ser utilizada na fase de planejamento estratégico, e deve ser empregada para o desenvolvimento de um novo ciclo de vida do sistema produto-serviço (RIBEIRO, 2011).

Diversos modelos para ciclos de vida de sistemas produto-serviço estão disponíveis. A questão da sustentabilidade nos processos de produção foi norteadora para a escolha dos modelos aqui apresentados. Em Ribeiro (2011), existe uma vasta referência sobre esse tema de desenvolvimento de produtos e serviços, dentre outros modelos existentes. Para a realização do presente trabalho, é adotado o modelo proposto por Vezzoli e Manzini (2008).

\footnotetext{
Uma maneira de conceber o desenvolvimento de novos produtos tendo como objetivo que, durante todas as fases de projeto, sejam consideradas as possíveis implicações ambientais ligadas às fases do próprio ciclo de vida do produto (pré-produção, produção, distribuição, uso e descarte) buscando assim, minimizar todos os efeitos negativos possíveis (MANZINI; VEZZOLI, 2002, p.23).
}

Vezzoli e Manzini (2008) iniciam seu livro com um conceito para ecodesign. Para os autores, ecodesign é o design com base em critérios ecológicos. Manifesta-se, por conseguinte, através da expressão composta de conjunto de atividades de concepção, em que se asseguram as questões ecológicas como abordagem para redesenhar seus próprios produtos. Esses conceitos não devem apenas ser aplicados aos produtos (considerando material, forma e função), mas também ampliados para os sistemas de produção, isto é, todos os processos de bens, serviços e comunicação que são utilizados pelas organizações.

O design do ciclo de vida ou life cycle design (LCD), proposto por Vezzoli e Manzini (2008), tem por finalidade a redução do impacto ambiental relacionado ao ciclo de vida do produto, já que considera todas as etapas do desenvolvimento de um produto e as suas respectivas trocas com o meio ambiente. Sendo assim, para os autores, o desenvolvimento de um produto com características sustentáveis deve estar associado ao LCD e o idealizador do projeto deve estar atento a todas as etapas do ciclo de vida do produto, de acordo com o esquema apresentado na Figura 1. 


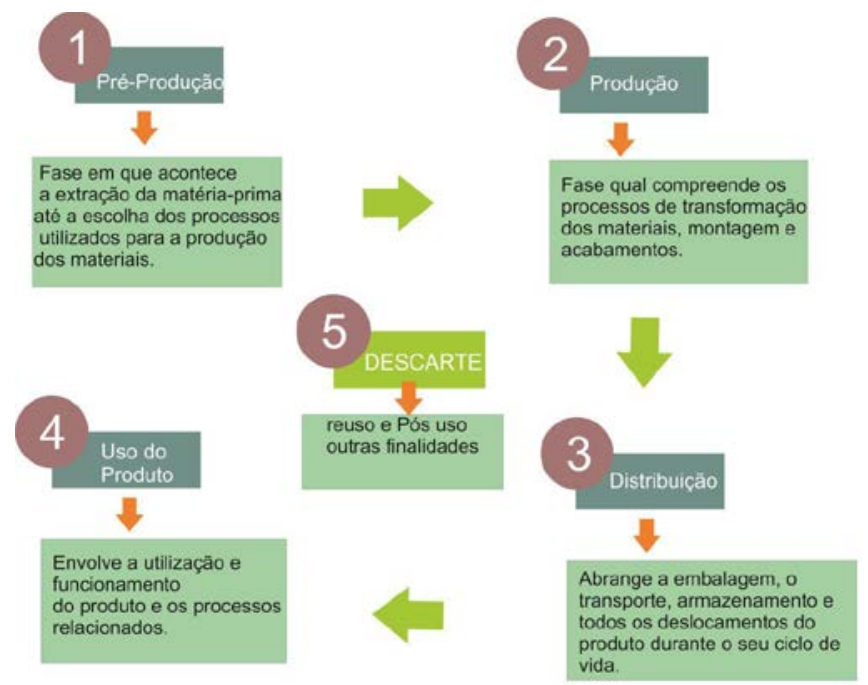

Figura 1 - Esquema do Design do Ciclo de Vida de Produto.

Fonte: Adaptado de Vezzoli e Manzini (2008).

De acordo com Vezzoli (2010), no ciclo de vida do produto, os processos relativos às fases do ciclo devem ser considerados como uma unidade. Para o autor, são analisadas cinco fases do ciclo de vida: (1) Pré-produção: identificação dos recursos para suprimento; (2) Produção: processo de montagem e acabamento; (3) Distribuição: embalagem, transporte e armazenagem; (4) Uso do produto: relação de uso do consumidor com o produto; (5) Descarte do produto: diferentes destinos possíveis para o produto (Figura 2).

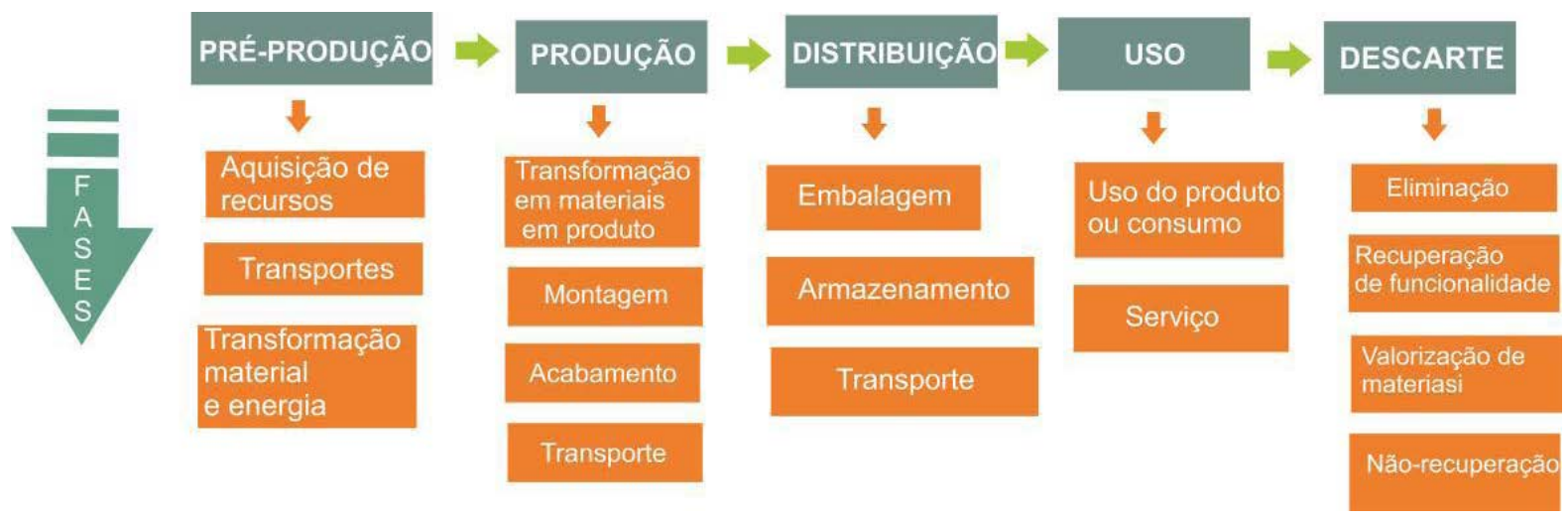

Figura 2 - Esquema do Design do Ciclo de Vida de Produto com Sub Fases Fonte: Adaptado de Vezzoli e Manzini (2008).

$\mathrm{Na}$ visão do o autor, é legítimo falar em um design do ciclo de vida, cujo objetivo é reduzir a utilização de matéria e energia, assim como o impacto de emissões ou resíduos pelos processos de cada etapa do ciclo de vida do produto. Isso ocorre porque, segundo o mesmo, os pressupostos econômicos e ambientais de uma abordagem de desenvolvimento do ciclo de vida buscam intervir na origem, de forma a prevenir as emissões perigosas e reduzir o consumo de recursos. É mais efetivo e menos custoso prevenir os danos ao ambiente nesse estágio de projeto, do que tentar remediá-los depois que o produto já está no mercado.

Muitas ações de sustentabilidade estão estritamente ligadas à economia e geração de lucro, tornando mais atrativo atingir determinados objetivos. Isso se 
relaciona a metas como a minimização de matéria-prima utilizada e a otimização dos processos de transportes, acarretando uma economia de materiais e energia. Assim, o ecodesign surge para transformar os produtos, desde sua concepção, em direção à sustentabilidade ampliada. Uma das indagações que podem surgir é de que forma o design de um produto é capaz de caracterizá-lo como um projeto sustentável.

\subsection{Ciclo de vida do Sistema Produto-Serviço em Acessórios de Moda}

Na visão de Salcedo (2014), os estudos e orientações para os designers, em relação às questões sociais e ambientais que devem ser consideradas para 0 desenvolvimento de produtos da área de moda, envolvem desde o ciclo de vida dos processos, até o descarte ou reuso dos produtos. Neles são destacados a importância de: uso e escolha de materiais e fibras que agridam menos ao meio ambiente, o desenvolvimento de peças reutilizáveis, formas de tornar o processo da moda menos acelerado, redução das agressões geradas pelos ciclos de vida de produção têxtil, e atenção aos impactos sobre a água e solo. A indústria da moda e acessórios tem o agravante de ser atrelada ao consumo exagerado de produtos. A cada ano lança no mercado pelo menos duas coleções (inverno e verão) para cada linha do vestuário.

No caso de acessórios, esse ciclo é um pouco distinto, porque não existe o processo de lavagem. Algumas esferas essenciais para sua composição compõem esse ciclo. A primeira etapa consiste na seleção da matéria-prima, na busca de diferentes formas de extração dos materiais, sejam eles de origem vegetal e/ou animal. Para o couro, há um tratamento por cromo ou tanino, visando a sua produção em série. Outra etapa do processo é o design como forma de abordagem projetual, responsável por pensar desde a composição do produto, até o reuso do acessório, criando o seu diferencial. Em seguida, está a esfera da confecção dos acessórios, logística, distribuição, e uso dos mesmos, levando em consideração sua vida útil, descarte e reuso. Aqui, novamente o design marca presença.

É possível, portanto, contabilizar toda a vida de um produto como um conjunto de atividades e processos, cada um deles absorvendo certa quantidade de matéria e energia, operando séries de transformações e liberando emissões de natureza diversa (MANZINI \& VEZZOLI, 2005). Considerando o ciclo de vida de produto juntamente com as esferas ambiental, social e econômica, e suas fases de ciclo de anel fechado (MANZINI \& VEZZOLI, 2002), um passo na moda para seguir no caminho da sustentabilidade é aquele em que cada indivíduo e, portanto, cada consumidor em potencial - "agindo com base em seus próprios valores, em seus próprios critérios de qualidade e em sua própria expectativa de vida - fará escolhas que também sejam as mais compatíveis com as necessidades ambientais" (MANZINI \& VEZZOLI, 2008, p.65).

Por suas características, por exemplo, a sazonalidade das estações, os produtos de moda parecem ter um ciclo de vida mais curto do que outros produtos. A utilidade e duração desses produtos dependem de estarem "na moda", ou seja, em conformidade com o padrão vigente. Assim, para uma análise menos superficial do ciclo de vida de um produto da moda, é preciso ir além do entendimento de que o produto começa e termina apenas ao "entrar ou sair da moda". Dado isso, a visão de ciclo de vida com o qual que este trabalho dialoga é ampliado, considerando, em princípio, a própria extração da matéria-prima. Com referência ao ciclo de vida dos produtos de acessórios de moda em couro, segue o esquema apresentado na Figura 3. 


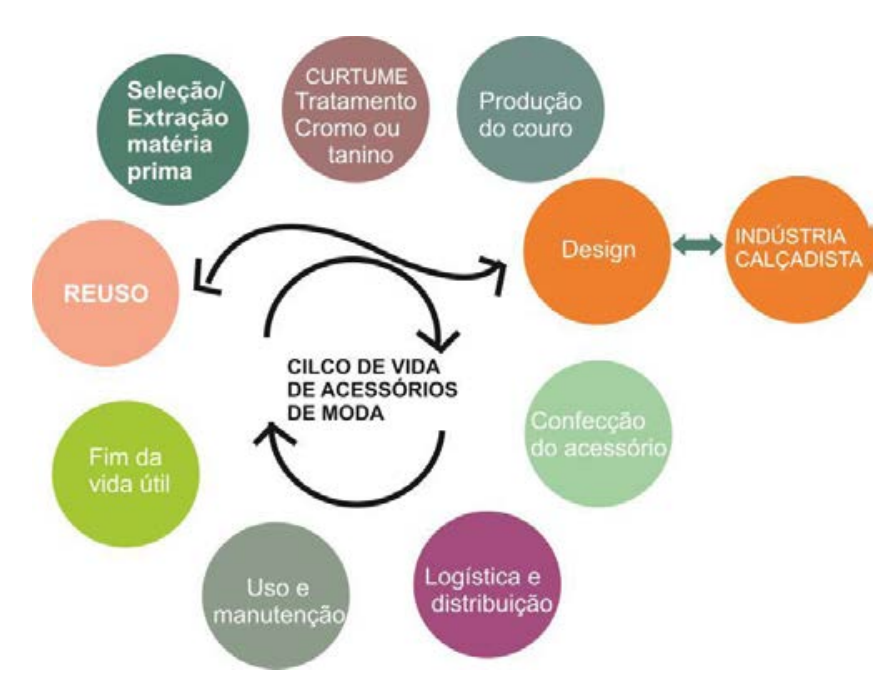

Figura 03 - Elaboração Ciclo de Vida Produtos em Acessórios em Couro

Fonte: Elaborado pelas autoras com base na pesquisa realizada.

\subsection{Estudo de caso}

A empresa objeto deste estudo será chamada de XX Acessórios de Moda, com a finalidade de preservar seu anonimato e identidade. Optante pelo Simples Nacional, a XX Acessórios de Moda é uma micro-empresa composta por duas sócias-diretoras e seis funcionários. Sua origem ocorreu no ano de 2010, a partir da vontade das fundadoras de transformar retalhos de roupas em algum produto que fosse inovador. O seu portfólio, a partir do aproveitamento "do que sobra do couro das fábricas de calçados", é composto pelos seguintes produtos e acessórios: vestuário (camisetas, regatas, saia e vestido), carteiras, bolsas, lixo para carro, necessaires, porta cheques, porta iPads, e porta óculos, dentre outros.

O estudo de caso foi iniciado com a observação contextual, a partir do acompanhamento de uma semana típica na empresa. Em seguida, foram realizadas entrevistas semiestruturadas com empresários, funcionários e clientes, que serviram como um filtro para identificar os dados que tiveram maior ocorrência. Os dados coletados foram analisados conforme a teoria fundamentada nos dados, TFD (GLASER \& STRAUSS, 1967; CRESWELL, 2007; CHARMAZ, 2009), resultando em sistematizações, incluindo agrupamentos de insights ou achados, categorias emergentes e princípios/critérios norteadores para o design amplamente sustentável. O workshop de cocriação envolveu os diferentes grupos de participantes, além de especialistas nas áreas de design de moda e marketing, gerando, a partir da apresentação dos resultados da pesquisa, diversos conceitos e cenários alternativos.

Com base nos ensinamentos de Manzini e Vezzoli (2008), os dados analisados foram organizados de acordo com as seguintes fases do ciclo de vida do produto:

- Na Pré-produção: a) A empresa desconhece a procedência dos insumos que adquire dos fornecedores; b) A empresa potencializa ao máximo o aproveitamento dos insumos; c) A empresa utiliza como insumo um material já descartado.

- Na Produção: a) A empresa desenvolveu técnicas não agressivas na confecção dos produtos; b) Há interferência industrial na montagem dos produtos. 
- Na Distribuição: a) A distribuição é feita com caixas de papelão doadas de parceiros; b) A empresa possui um baixo estoque de produtos; c) As caixas, onde os produtos são acondicionados para envio, são doadas; d) A empresa minimiza a utilização de embalagens.

- No Uso: a) As informações da empresa sobre critérios de sustentabilidade concentram- se no topo da hierarquia organizacional.

- No Descarte: a) Após a sua utilização, os produtos não retornam a empresa; b) Os resíduos resultantes da produção são doados a uma escola de samba de uma comunidade carente.

De maneira geral, de acordo com a fala das empresárias, funcionárias e clientes, a sustentabilidade dessa empresa se dá por meio da utilização de sobras de couro, e pela imagem dos produtos, que parecem associar o rústico do couro, apesar da delicadeza de diversas peças, a um produto de certa forma "natural".

Os dados provenientes das entrevistas e da observação contextual possibilitaram o cruzamento das informações levantadas com o ciclo de vida do sistema produto-serviço apresentado por Manzini e Vezzoli (2008). Por conseguinte, foi elaborada uma sistematização das informações de modo que fosse fornecido fidedignamente o cenário atual da XX Acessórios de Moda. Assim, as fases do ciclo de vida do produto, que atualmente abrangem a empresa, foram apresentadas e, posteriormente, através de critérios norteadores do design, potencializados em uma ampliação deste ciclo, no sentido de expandir o seu entendimento sobre sustentabilidade. Isso é, as fases atuais foram ampliadas considerando-se outros aspectos além do apresentado inicialmente pela empresa, conforme suas atividades atuais. Tal intento foi possível por conta da compilação realizada na literatura sobre as possíveis dimensões de sustentabilidade em ciclos de vida dos produtos.

Nesse sentido, pode-se considerar o cenário atual do Ciclo de Vida do ProdutoServiços da XX Acessórios de Moda da seguinte forma (Figura 4):

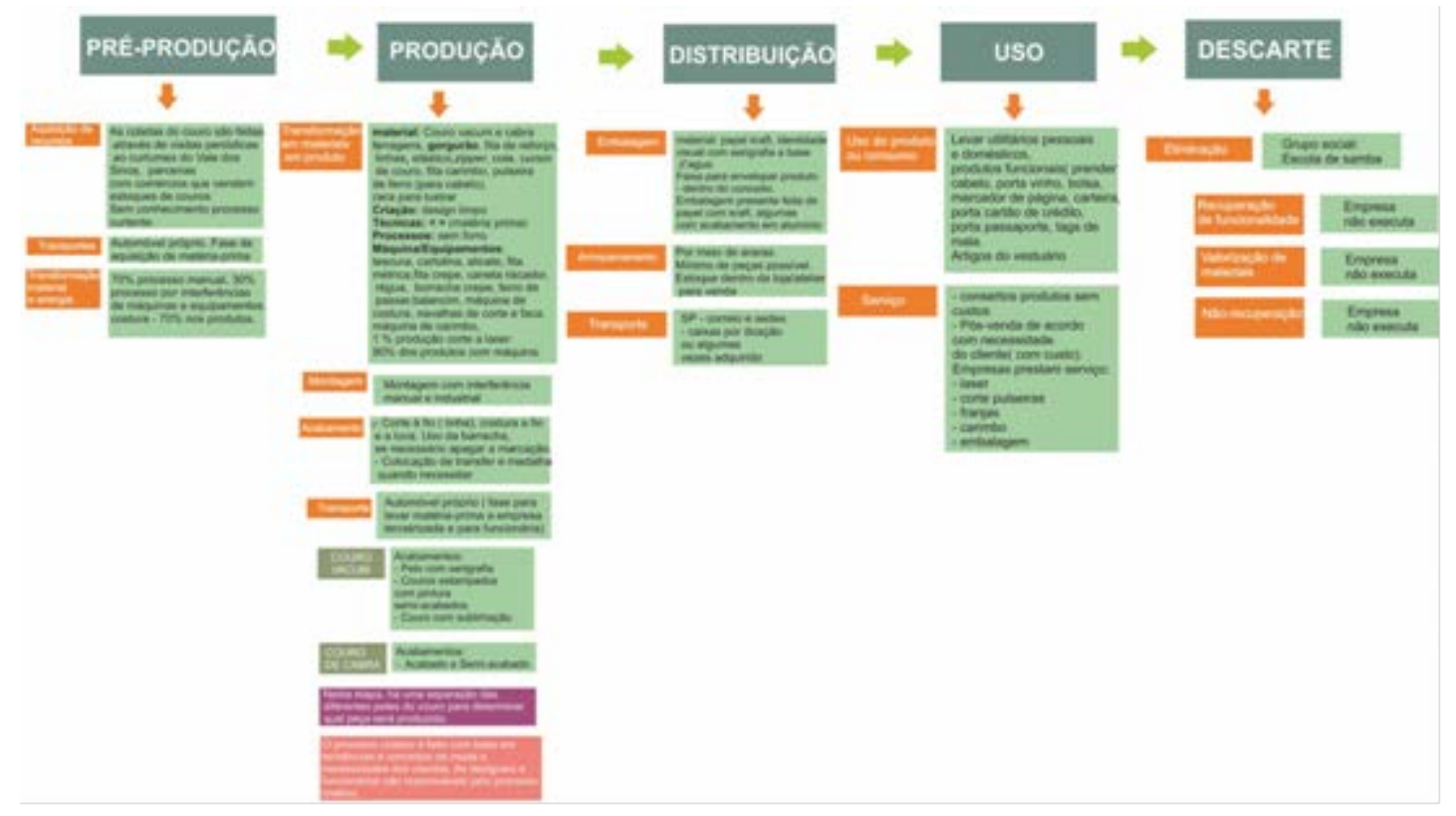

Figura 4 - Ciclo de Vida Produtos-Serviços atual da XX Acessórios de Moda.

Fonte: Elaborado pelas autoras com base na pesquisa realizada 
Na figura 5 são apresentadas, em primeiro plano, a sistematização com Ciclo de anel fechado partindo de uma extração consciente, uma produção consciente, um consumo consciente, uma distribuição consciente e, por fim, um reuso consciente. Tal sistematização compreende uma conjuntura de processos de ciclo de vida do sistema produto-serviço de Manzini e Vezzoli (2008), ciclo de vida de produtos de moda de Berlim (2012) e particularidades do setor do couro animal, compreendendo as esferas ambiental, social e econômica. Adicionalmente, inclui conceitos e referenciais do design estratégico, design thinking, ISO 14001, slow fashion, design social, logística reversa e design for disassembly (MANZINI \& VEZZOLI, 2002; ABNT, 2004; MOURA, 2010; BROWN, 2009; BERLIM, 2012).

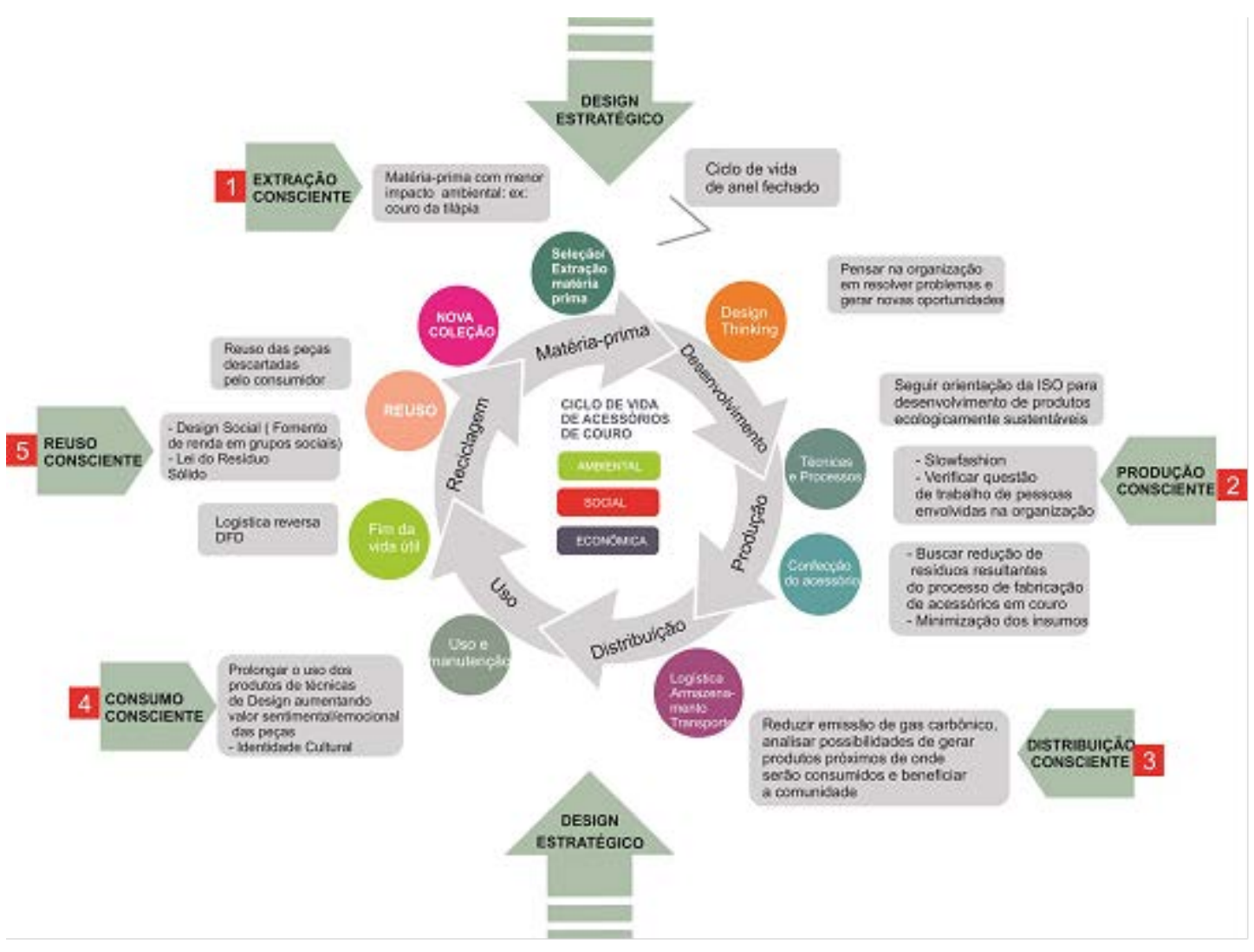

Figura 5 - Sistematização da Abordagem Projetual Juntamente com Ciclo de Vida do Sistema ProdutoServiço de Moda Visando a Sustentabilidade Ampla.

Fonte: Elaborado pelas autoras com base na pesquisa realizada.

$\mathrm{Na}$ sistematização de metodologia para análise e projetação das sustentabilidades na indústria da moda e acessórios em couro podem ser inseridos cenários em qualquer uma das etapas do ciclo de vida do sistema produto-serviço. Portanto, foi inserido, na sistematização, a etapa do descarte, a qual apresenta os resultados e estratégias para possíveis melhorias na empresa. Nesse caso simboliza: (a) Catálogo de produtos da empresa, (b) Oficina de consertos de peça, (c) Catálogos de possíveis tratamentos e processos de revitalização, (d) Glossário técnico da empresa, (e) Trabalho na superfície em peças prontas, (f) Workshop e curso de reuso. 


\section{CONCLUSÃO}

A interpretação dos resultados obtidos foi responsável por gerar modelos e projetações para sustentabilidade ampla. Conforme previsto no objetivo geral, este estudo apresentou sistematizações e abordagens projetuais do design para três dimensões da sustentabilidade, considerando as esferas ambiental, social e econômica, bem como os ciclos de vida de produtos de moda, observando especificamente os acessórios em couro. Os resultados deste estudo foram influenciados através de estratégias para cada uma das esferas da empresa.

$\mathrm{Na}$ primeira fase do ciclo de vida do sistema produto-serviço está a préprodução, referindo-se a como a matéria prima é extraída. Cabe, portanto, identificar de onde é extraído o material que será utilizado em cada peça. Além de observar de onde são extraídas tais matérias primas, também é relevante verificar quais comunidades estão envolvidas, se a extração agrega valor à inovação social, e se é um produto que, caso colocado em aterro sanitário, gerará toxicidade dos solos, dentre outros itens. $\mathrm{Na}$ análise das questões de sustentabilidade ambiental para essa etapa, incluem-se: seleção de matéria-prima, redução de uso de materiais poluentes e agressivos ao meio ambiente, considerações quanto à pré-produção de materiais, nível de agressão ao meio ambiente e questões sociais. A fase seguinte é de transformação dos materiais, montagem e criação das peças. Nessa fase, devem-se aplicar as recomendações da ISO 14001 'para o desenvolvimento de produtos verdes. E, dessa forma, será possível garantir o desenvolvimento de produtos com base no ecodesign. Mas isso não é o suficiente para se alcançar a sustentabilidade nas demais esferas: econômica e social. Para o desenvolvimento das peças, é fundamental avaliar o que será gerado como resíduo da produção. No caso de recorte de matéria-prima, como o couro, por exemplo, cabe buscar soluções inovadoras, no sentido de usar mais do mesmo e desperdiçar menos.

A questão social é presente nas etapas de pré-produção e produção, além do descarte, assim sendo, estão associadas às comunidades de entorno, referindo-se aos exemplos de conceitos do design social, tal como de onde são extraídas as matériasprimas, por exemplo. No caso de uso de resíduos, é possível mobilizar pessoas a formarem cooperativas e realizarem a pré-seleção de material a ser utilizado na área da moda. E, dessa forma, pode-se promover uma ação de inovação social, oportunizando uma nova fonte de renda para as pessoas que vivem próximas das áreas de indústria de calçados e que possam ter uma nova fonte de renda. No caso de uso do couro do peixe, beneficiam-se as comunidades que dependem em uma finalização dos resíduos da pesca (QUARESMA, 2013). É possível ainda, capacitar as pessoas com formas de uso de resíduos no sentido de promover as comunidades criativas nas dependências das indústrias de calçados. Ainda no descarte, conclui-se que o ciclo da empresa estudada é de "anel aberto", (MANZINI \& VEZZOLI, 2002) pois ocorre um desvio durante a fase de retorno dos produtos à empresa. Assim, sugere-se implantar a logística reserva utilizando o design for dissassembly no processo de produção, para facilitar desmontagem no reuso da peça.

Na distribuição consciente, desenvolve-se através da inspiração dos processos de que eram realizados antes da chegada da indústria. Nessa época, utilizavam-se os serviços e mão de obra mais próximos aos locais, evitando a busca de fornecedores em grandes distâncias. Aconselha-se fazer um levantamento do que é necessário em termos de fornecedores e buscar os mais próximos. É importante tentar reduzir os 
gastos com logística para a distribuição dos produtos. Essas duas ações beneficiam questões sociais e ambientais. Nessa fase, a empresa já desenvolve ações sustentáveis no momento em que reaproveita caixas doadas por parceiros.

Diante de tantas inquietações em explorar toda a cadeia, desde as fases, os ciclos, e as esferas, esta pesquisa descobriu uma forma, através das sistematizações, com finalidade de ampliar a sustentabilidade da empresa estudada, além de uma projetação de cenários visando estratégias para agregar valor social, ambiental e econômico. A adaptação do ciclo de vida de Mazini e Vezzoli (2008) foi essencial, e serviu de base para a projetação de um novo ciclo de vida do sistema produto-serviço, visando sistematizações para a sustentabilidade ampla. Ainda vale o aproveitamento desta pesquisa, a fim de possibilitar a criação e novos cenários nas diversas fases do ciclo de vida, visando produtos e serviços.

Considerando a possibilidade deste estudo ser um auxílio para outros pesquisadores, assim como para outras empresas que tenham o objetivo de ampliar a sustentabilidade, reforça-se a necessidade de continuar investigando as possíveis esferas em suas variadas fases.

\section{REFERÊNCIAS}

ABNT. Associação brasileira de Normas Técnicas. Sistemas da gestão ambiental Requisitos com orientações para uso (ABNT/NBR ISO 14001), 2004. Disponível em: $<$ http://www.labogef.iesa.ufg.br/labogef/arquivos/downloads/nbr-iso-14001 2004_70357.pdf>. Acesso: 18 jun. 2006.

BELLGRAN, M.; SAFSTEN, K. Production Development Design and Operation of Production Systems. London : Springer, 2010.

BERLIM, L. Moda e sustentabilidade. Uma reflexão necessária. 1. Ed Estação das Letras e Cores, 2012.

BEST, K. Design management: Managing design strategy, process and implementation. Lausanne: AVA Publisher, 2006.

BRASIL. Lei Federal n 12.305, de 2 de agosto de 2010. Institui a Política Nacional de Resíduos Sólidos; altera a Lei n 9.605, de 12 de fevereiro de 1998; e dá outras providências. Diário Oficial [da República Federativa do Brasil], Brasília, DF, CXLVII, n. 147, 03 de ago. 2010. Seção I, p. 3-7.

BROWN, T. Change by design: how design thinking transforms organizations and inspires innovation. Nova lorque: Harper Collins Publishers, 2009.

CHARMAZ, K. A. A construção da Teoria Fundamentada nos Dados. Porto Alegre: Artmed, 2009.

CRESWELL, J. W. Projeto de Pesquisa: métodos qualitative, quantitative e misto. Porto Alegre: Artmed Bookman, 2007.

GLASER, B.G.; STRAUSS, A.L. The discovery of Grounded Theory. Chicago: Aldine, 1967. HIRSCHHORN, j. JACKSON, T. \& Bass, I, Towards Prevention. The Emerging ParadigmClean Production Strategies. Ed. Jackon, 1993. 
MANZINI, E. O desenvolvimento de produtos sustentáveis: os requisitos ambientais dos produtos industriais. São Paulo: Editora da Universidade de São Paulo, 2005.

MANZINI, E. Design for Environmental Sustainability. London: Springer-Verlag, 2008.

MANZINI, E., VEZZOLI, C. Product-service systems and sustainability. Opportunities for sustainable solutions. Paris: UNEP Publisher, 2002.

Product-service systems and sustainability: Opportunities

for sustainable solutions. Milão: INDACO, 2004.

O Desenvolvimento de Produtos Sustentáveis. São Paulo: Editora

da Universidade de São Paulo, 2005.

O Desenvolvimento de Produtos Sustentáveis. Os requisitos

ambientais dos produtos industriais. Edusp. São Paulo. SP. 2008.

MCDONOUGH, W.; BRAUNGART, M. Applying the principles of green engineering to cradle to cradle design. Environmental Sicence Technology, 2004.

MOURA, H. Design e gestão estratégica da inovação no Brasil. Anais do 9o P\&D, Congresso Brasileiro de Pesquisa e Design, São Paulo, 2010.

Texto de Apresentação do Projeto Memória Técnica da Rio+20.

Rio de Janeiro: Governo do Estado do Rio de Janeiro, 2013.

QUARESMA, D. M. M. Etnodesign e inclusão social: um olhar sobre experiências em design de artesãs da Ilha Pintada. Seminário de Pesquisa e Extensão Uniritter. Porto Alegre, 2013.

RIBEIRO, V. C. Aplicação do Conceito Sistema Produto-Serviço (PSS) no

Desenvolvimento Integrado de Produto. Dissertação (Mestrado) - Universidade Tecnológica Federal do Paraná. Programa de Pós-graduação em Engenharia Mecânica e de Materiais, Curitiba, 2011.

SALCEDO, E. Moda ética para um futuro sustentável. Espanha: Editora G. Gili, 2014. VEZZOLI, C. Cenário do design para uma moda sustentável. In. PIRES, Dorotéia B. (Org.). Design de moda: olhares diversos. São Paulo: Estação das letras e cores, 2008.

Design de sistemas para a sustentabilidade: teoria, métodos e ferramentas para o design sustentável de "sistemas de satisfação". Salvador: EDUFBA, 2010.

. Design e sistema de inovação para a sustentabilidade. In: CARLI, Ana

Mery Sehbe de; VENZON, Bernadete Lenita Susin. Moda, Sustentabilidade e Emergências. Caxias do Sul: Educs, 2012.

VEZZOLI, C.; CESCHIN, F. Sustainable product service systems for personal clothing care. Holsehold and Personal Care, Milano, v.4, n.2, p.24-29, dez.2008.

VEZZOLI, C.; WALKER, S. Light touch: The design of ephemeral objects of sustainable product design. The Journal of Sustainable Product Design, v. 3, n. 3-4, pp. 187-198, 2003.

WALKER, S. Light Touch - The Design of Ephemeral objects of Sustainable Product Design, 2003. 
WCED (United Nations World Commission on Environment and Development). Our common future: Report of the World Commission on Environment and Development (Brundtland Report), WCED, Switzerland, 1987. 